\title{
AN IMPROVED PRETREATMENT PROTOCOL FOR RADIOCARBON DATING BLACK PIGMENTS IN SAN ROCK ART
}

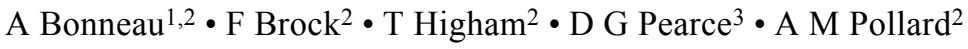

ABSTRACT. The dating of South African rock art using radiocarbon is a considerable challenge and only 1 direct date has so far been obtained, on black pigments from Sonia's Cave Upper, Boontjieskloof. The main problem with direct dating these paintings is the presence of calcium oxalates behind, on, and within the pigment layers. Calcium oxalates are formed through lichen and bacterial action on the rock face. These reactions can sometimes take place over long periods and can incorporate carbon of a younger age into the pigments. This study aims to date black pigments from a rockshelter, RSA TYN2 (Eastern Cape, South Africa), by removing the calcium oxalate contamination. Two different protocols were tried: density separation and acidification. The latter successfully removed calcium oxalates and was therefore applied to 3 black pigment samples from the rockshelter. After acid pretreatment, accelerator mass spectrometry (AMS) dating was undertaken on the remaining residues. Three results were obtained ( $2072 \pm 28 \mathrm{BP}, 2100 \pm 40 \mathrm{BP}$, and $2083 \pm 32 \mathrm{BP}$ ), which constitute the oldest results so far obtained for direct dates on South African rock art. The most likely calibrated date range for the painting at this site is between 2120 and $1890 \mathrm{cal}$ BP. The ages are in close agreement with each other and this consistency suggests that our preparation protocol has successfully removed the majority of the carbon contaminants.
\end{abstract}

\section{INTRODUCTION}

The San rock art of southern Africa is one of the best understood traditions of rock art in the world; detailed interpretations explain much of the imagery (e.g. Lewis-Williams and Pearce 2004). Occurrences are distributed over much of southern Africa south of the Zambezi and it is particularly prolific in the Drakensberg mountain range. A proper chronology has been a central concern of researchers for many years. In the 1960s and 1970s, much effort was put into the construction of relative chronologies based on stylistic differences (e.g. Pager 1971; Vinnicombe 1976). Unfortunately, none of these stylistic sequences seem to have been real, and have long been abandoned. More recently, attempts have been made to construct sequences of paintings using the Harris matrix technique (e.g. Russell 2000; Swart 2004). This technique, however, does not translate well to painted contexts, and tends to produce fallacious sequences (Pearce 2010a).

There are very few radiocarbon dates for San rock paintings; the most recent reviews of the dating evidence are those by Mazel (2009a,b). It has long been assumed that the black paints are based on mineral pigments rather than carbon, and so few attempts have been made to ${ }^{14} \mathrm{C}$ date the paintings. The majority of dates that we have are for collapsed wall paintings or loose painted stones dated by association from the layers of deposit in which they were found. The oldest dates for southern African paintings obtained in this manner are from the Apollo 11 shelter in southwestern Namibia. Three ${ }^{14} \mathrm{C}$ dates on material found in close proximity to 7 fragments of painted stones gave dates of between 27,500 and 25,500 BP (Wendt 1976: it is not entirely clear how these dates were interpolated from the adjacent ${ }^{14} \mathrm{C}$ dates, nor would they have been calibrated), leading to the claim that these represented the oldest African "art mobilier" known at that time. The oldest date so far obtained in this manner for collapsed wall paintings is $\sim 3600 \mathrm{BP}$ (uncalibrated) at Steenbokfontein Cave in South Africa (Jerardino and Swanepoel 1999). A few other, more recent examples have also been found. These are, of course, dates for the burial of the painted pieces rather than dates of painting.

${ }^{1}$ Université Michel de Montaigne Bordeaux III, Domaine Universitaire, 33600 Pessac, France. Permanent address: Archaeology laboratory, Laval University, 3 rue de la Vieille-Université, Quebec G1R 3T5, Canada. Corresponding author. Email: adelphine.bonneau@gmail.com.

${ }^{2}$ Research Laboratory for Archaeology and the History of Art, Dyson Perrins Building, South Parks Road, Oxford OX1 3QY, United Kingdom.

${ }^{3}$ Rock Art Research Institute, GAES, University of the Witwatersrand, Private Bag 3, WITS 2050, South Africa. 
The earliest attempt to directly date paintings was made by Denninger (1971) in which, using paper chromatography, he examined amino acids apparently derived from binders in paint. He contended that the rate of decomposition of amino acids differed, and by examining the amino acids present ages could be assigned to paintings. The technique was not further pursued.

The most concerted work on ${ }^{14} \mathrm{C}$ dating South African paintings has been undertaken in the KwaZulu Natal Drakensberg by Mazel and Watchman. They succeeded in obtaining 1 accelerator mass spectrometry (AMS) date on plant fibers found mixed into paint (Mazel and Watchman 1997). They argued that the fiber derived from plant sap used as a binder in the paint. The date calibrated to AD 1443-1653. They also ${ }^{14} \mathrm{C}$ dated layers of calcium oxalate found lying both over and under paintings (Mazel and Watchman 2003). Two dates on overlying layers calibrated to between approximately 1000 and 2000 BP; 6 dates on underlying layers came to between approximately 2000 and 4000 BP (Mazel and Watchman 2003: Table 2). These are minimum and maximum ages, respectively, not direct dates for the paintings.

The earliest, and until now only, direct dating of paint was from Sonia's Cave Upper, Boontjieskloof, obtained by AMS at the Oxford Radiocarbon Accelerator Unit in 1981 (OxA-515). It gave a ${ }^{14} \mathrm{C}$ determination of $500 \pm 140 \mathrm{BP}$ (van der Merwe et al. 1987). The imprecision of the result lends itself to a wide calibrated age range of AD 1323-1625 (68.2\% probability) and AD 1234-1802 ( $95.4 \%$ probability). Of the 9 samples of different colors from various sites in South Africa subjected to dating, only 1 black sample (of 2 studied) contained sufficient carbon after preparation for dating. The X-ray fluorescence (XRF) analyses of most of the samples showed a high concentration of calcium attributed to either the presence of calcium carbonates or to contamination from the cellotape used to mount the samples for XRF, but which could have included calcium oxalates.

This study by van der Merwe et al. (1987) is an important starting point for the ${ }^{14} \mathrm{C}$ dating of San paintings, in spite of the magnitude of the error and the uncertainty over the removal of the calcium oxalates. We aim to quantify the presence of calcium oxalates in the pigment samples using Fourier transform infrared (FTIR) spectroscopy so that we can be certain we have removed them prior to AMS ${ }^{14} \mathrm{C}$ dating.

\section{Site Description}

The work was conducted on a series of painted rock spalls from a single site. RSA TYN2 is a painted rockshelter in the Drakensberg Mountains of the Eastern Cape Province, South Africa (Figure 1). The rockshelter is about $25 \mathrm{~m}$ long, $3 \mathrm{~m}$ high, and $6 \mathrm{~m}$ deep. The shelter is painted through most of its length, although the majority of paintings are located towards the center of the shelter. A section of the painted shelter wall is spalling severely. A conservation project in 2008 and 2009 collected 154 painted flakes from the shelter floor (Pearce 2010b). Thirty-three of these, with the highest densities of paint, were selected for physical analysis (Bonneau et al. 2011). Five of these with black paint were subsequently chosen for ${ }^{14} \mathrm{C}$ analysis.

\section{Characterization of the Black Pigments}

Painted fragments from the samples collected from this site show 4 different colors: light red, dark red, pinkish red, and black. Analysis of these pigments is described in full in Bonneau et al. (2011), but the focus of this paper is on the black pigments. Nine black samples have been analyzed by Raman spectroscopy to determine their composition and by FTIR spectroscopy to detect possible contamination occurring in the pigments that could result in erroneous ${ }^{14} \mathrm{C}$ dates if not properly removed, and to check the efficacy of the removal process. The pigment samples were removed from the rock fragments by gentle scraping with a scalpel. These were changed between each sample. 


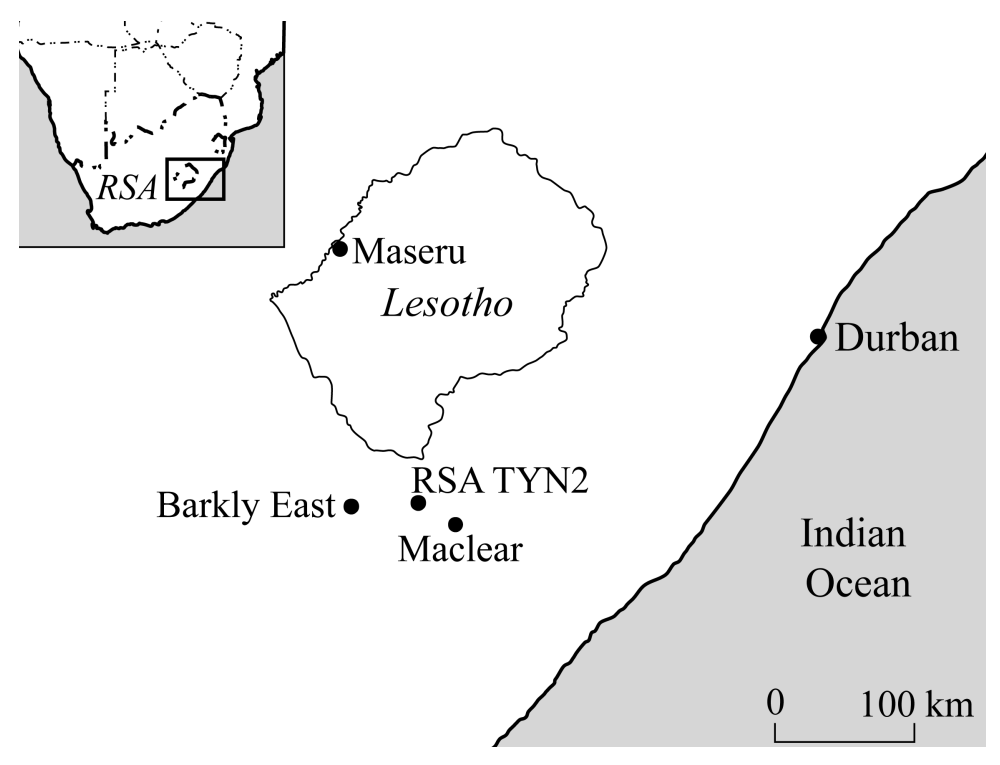

Figure 1 Site location

\section{Raman}

All 9 black samples were analyzed using a Bruker Senterra Raman system, equipped with a microscope with 3 lenses $(\times 10, \times 20, \times 50)$. Its spectral resolution was $3 \mathrm{~cm}^{-1}$. The laser used was a near infrared, $785 \mathrm{~nm}$, with a power of $10 \mathrm{~mW}$. Raman spectroscopy was also carried out using a Horiba Infinity spectrometer with a green $(531 \mathrm{~nm})$ laser. The spot size used was around $3 \mu \mathrm{m}$ with a maximum power of $4.5 \mathrm{~mW}$ at the sample. The black pigments were analyzed directly onto the surface of the painted rock fragments, and also in cross-section ( 2 cross-sections having been prepared from samples with black pigments). Two different lasers were used (and so 2 different instruments) to have a better knowledge of the composition of the pigments: green laser excitation giving the main compounds of the pigments, and the near-infrared laser giving information on the possible organic and mineral contamination. The spectra of the black pigments (using the Horiba Infinity spectrometer with a green laser) show 2 principal peaks at 1360 and $1580 \mathrm{~cm}^{-1}$ and 2 much weaker ones at 1474 and $1005 \mathrm{~cm}^{-1}$ (Figure 2).

The peak at $1474 \mathrm{~cm}^{-1}$ corresponds to the contribution of calcium oxalates. The peak at $1005 \mathrm{~cm}^{-1}$ indicates the contribution of gypsum. The first 2 peaks $\left(1360\right.$ and $\left.1580 \mathrm{~cm}^{-1}\right)$ correspond to an amorphous carbon such as one can find in bone black, ivory black, or lampblack, also called carbon black (Stuart 2007). Identification as bone black or ivory black can be dismissed here because in these materials a peak also appears towards $960 \mathrm{~cm}^{-1}$, corresponding to residual phosphate, $\mathrm{PO}_{3}{ }^{4-}$, coming from hydroxylapatite (Edwards et al. 2004). If charcoal had been used, the texture of the pigment would be coarser and there would be pieces of charcoal still visible under the electron microscope, even if they had been crushed. Since no such fragments were observed, we are left with the probability that the pigment is carbon black.

Carbon black is a pigment used since prehistoric times. It has been identified in French and Spanish prehistoric caves (Garate et al. 2004; Menu 2009). It consists of the incomplete combustion products of varied substances such as wood, charcoal, cores of fruits, resins, oil, fat, etc. Whatever the preparation, the residual pigment has a very important coloring and covering capacity and a particularly fine granulometry. 


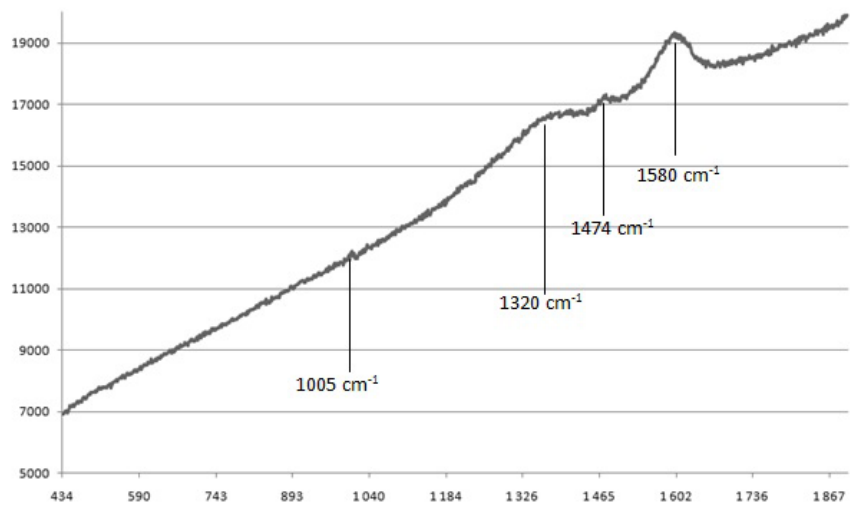

Figure 2 Black pigment Raman spectrum ( $x$ axis: wavenumber $\mathrm{cm}^{-1} ; y$ axis: Raman intensity).

\section{Fourier Transform Infrared (FTIR)}

FTIR analyses were carried out with a Bruker Vertex FTIR, equipped with a diamond ATR system. The spectra were acquired with 32 scans over a range of 400 to $4000 \mathrm{~cm}^{-1}$. The spectral resolution was $4 \mathrm{~cm}^{-1}$. A typical spectrum for the black pigment samples is given in Figure 3. Peaks at 1616, 1315 , and $779 \mathrm{~cm}^{-1}$ and those around $3600-3400 \mathrm{~cm}^{-1}$ are indicative of calcium oxalates (whewellite and weddellite). Peaks at $1144,1114,1092$, and $661 \mathrm{~cm}^{-1}$ are those of calcium sulfates and the peaks at $1047,1006,597,460,433$, and $420 \mathrm{~cm}^{-1}$ those of orthoclases and anorthoclases. Only the peak at $1420 \mathrm{~cm}^{-1}$ is recorded for calcite.

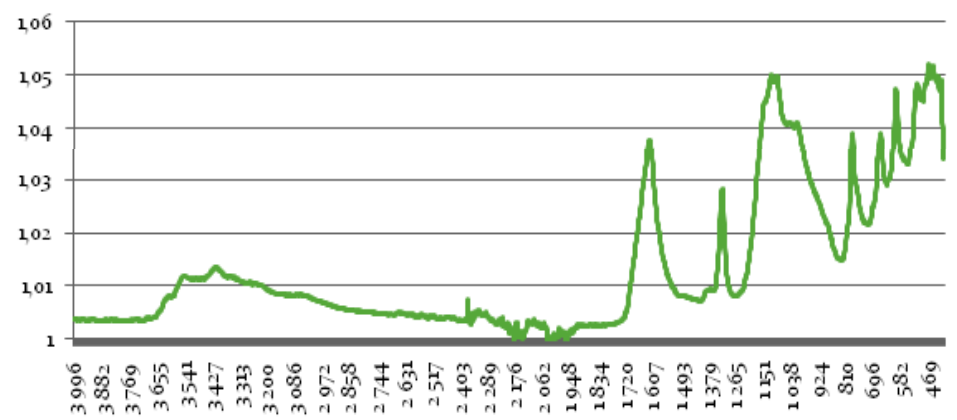

Figure 3 Black pigment FTIR spectrum ( $x$ : wavenumber $\mathrm{cm}^{-1} ; y$ : FTIR intensity)

The black pigments in this study are therefore carbon black, which means that they were made by the incomplete combustion of organic compounds. It is most likely that they were made a short time before use. However, analysis also shows the presence of calcium oxalates, which are weathering products, made mainly by the action of lichens and bacteria on the pigment layers and the rock face (Watchman 1990) or by a reaction between rain and the binders (J Ambers, personal communication, 2010). As lichens and bacteria need specific conditions to develop, calcium oxalate formation can take place over many years. This can therefore add carbon to the pigments that is potentially much younger than the original, and hence the oxalates must be removed prior to dating. 


\section{Preliminary Tests for Removal of Calcium Oxalates}

Various tests were considered with the aim of removing calcium oxalates from the pigments. The first test considered was oxidation under oxygen plasma, developed by M W Rowe (Russ et al. 1991). This technique works by transforming noncrystalline carbon (such as charcoal, carbon black, binders, etc.) into $\mathrm{C}_{2} \mathrm{O}_{4}$ by the action of an oxygen plasma. Since calcium oxalates are crystalline, they are not oxidized by the plasma (M W Rowe, personal communication, 2010). Nevertheless, this technique can oxidize all the other organic compounds on the surface of the sample, such as binders (Russ et al. 1991; Livingston et al. 2009) as well residues and other contaminants incorporated into the sample during its time on the floor of the rockshelter. Since this technique was not available at Oxford, the number of black samples available was small, and the risk of oxidizing compounds other than the carbon of the pigment itself was high, this possibility was not tried.

One method tested was density separation. This technique has been used to separate calcium carbonates for ${ }^{14} \mathrm{C}$ dating of shells (Douka et al. 2010). Tests were carried out with artificial mixtures of charcoal and calcium carbonates (ratios of 3:2, 7:3, 4:1 charcoal to $\mathrm{CaCO}_{3}$ ), because no calcium oxalates were available at the beginning of the tests. The density of powdered charcoal is 1.5 and of calcium carbonates is 2.7 , whereas calcium oxalates have a density ranging between 2 and 2.2. The 2 substances are separated using sodium polytungstate (SPT), which has a density that can be varied between 1.1 to $3.1 \mathrm{~g} \mathrm{~cm}^{-3}$ with the addition of water. For our tests, the density of the SPT was set at 1.9 , which should separate charcoal from both calcium carbonate and calcium oxalates. The tests were completely successful, with infrared spectra proving the absence of calcium carbonates after separation (Figure 4). There are, however, 2 major problems with this method. The first is the need to recycle the SPT because it is very expensive, and it is therefore difficult to ensure that no residual carbon remains that could contaminate samples prior to ${ }^{14} \mathrm{C}$ dating. The second is the assumption that the calcium carbonates (and also the calcium oxalates) are not chemically bound to the black pigment, which cannot be proved.

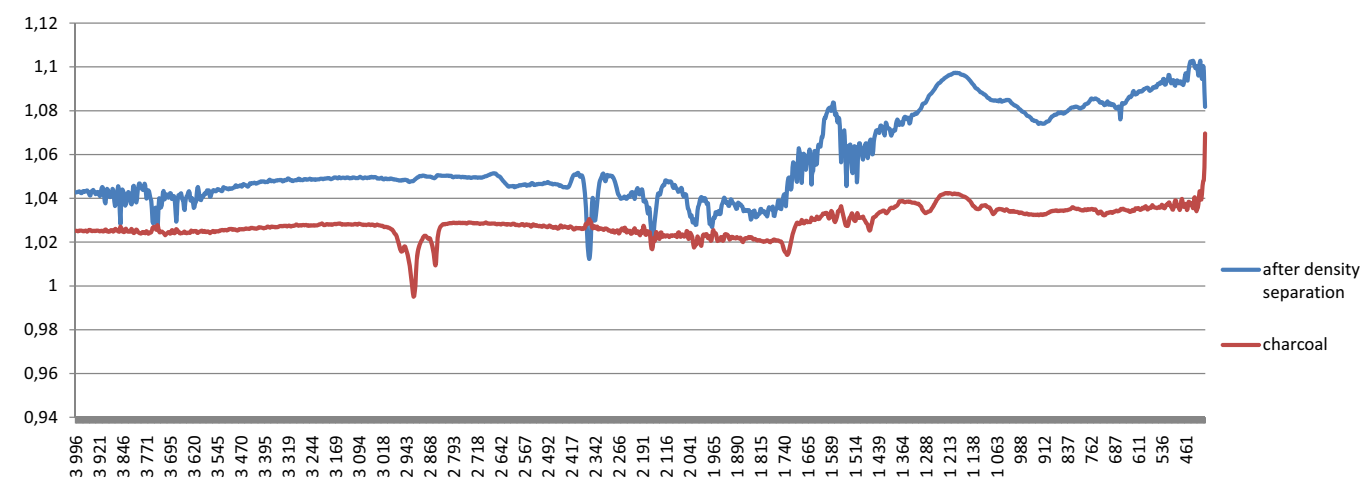

Figure 4 Spectra FTIR of the mixtures after density separation ( $x$ : wavenumber $\mathrm{cm}^{-1} ; y$ : FTIR intensity)

In terms of chemical pretreatment, 2 tests were carried out in parallel: one with hydrochloric acid, which is the first part of the ABA protocol already developed for the preparation of ${ }^{14} \mathrm{C}$ charcoal samples (Brock et al. 2010), and one treatment with sulfuric acid following the suggestion given by Jeffery (1975), who states that calcium oxalates can be dissolved by a sulfuric acid solution (1M), but without giving any details about time and heating. Trials were initially carried out using $5 \mathrm{mg}$ and $10 \mathrm{mg}$ of calcium oxalate (in mineral form, weddellite and whewellite, as identified by FTIR and Raman analysis) to see if they were dissolved by the acids, and if so, after how much time. 
These 2 mass values were chosen because they approximate the expected mass of calcium oxalates present in the pigments, which from the calcium in the quantitative SEM data seems to be around $30-40 \%$. For the 2 acids, after $1 \mathrm{hr}$ (at $80{ }^{\circ} \mathrm{C}$ for the hydrochloric acid and at $65{ }^{\circ} \mathrm{C}$ for the sulfuric acid), no remaining calcium oxalates were observed, only a transparent solution.

Tests were then carried out for each acid, using the same protocol and times as described above, with artificial mixtures of charcoal, calcium oxalates, and calcium carbonates (in the ratios 1:1:1, 2:1:1, $3: 1: 1$, respectively). Figure 5 shows the FTIR spectra of the sample before and after acidification. The peaks of calcium oxalates $\left(1620,1396\right.$, and $\left.1317 \mathrm{~cm}^{-1}\right)$ and of calcium carbonates $(1429,877$, and $\left.713 \mathrm{~cm}^{-1}\right)$ both disappeared (in both acids) and the remaining peaks $(2506,1360,1318,1126$, 908 , and $789 \mathrm{~cm}^{-1}$ ) are not those of the oxalic acid, but are those present initially in the charcoal. The results of these treatments are therefore conclusive.

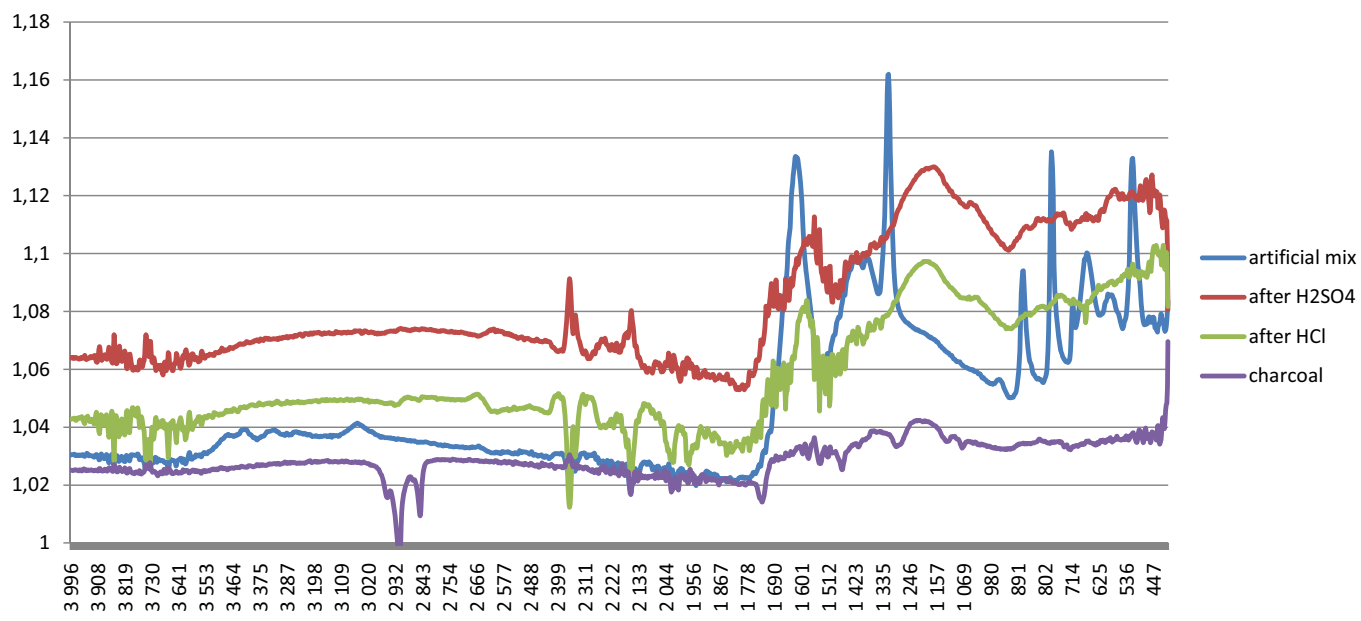

Figure 5 Spectra FTIR of the mixtures (charcoal, calcium carbonates, and calcium oxalates at 1:1:1) after acid treatments ( $x$ : wavenumber $\mathrm{cm}^{-1} ; y$ : FTIR intensity).

Two samples of black pigments (RP/2009/003/2, $8 \mathrm{mg}$, and a part of RP/2009/003/13, $13 \mathrm{mg}$ ) were then prepared using the protocols developed for each acid. The results were again examined by FTIR, showing conclusively that all the calcium oxalates were removed (Figure 6). The spectra show results identical to those obtained on the artificial mixtures. We conclude that both protocols work for our pigments. For the preparation of the remaining samples, we decided to use the protocol with hydrochloric acid because all the products of the reaction are soluble in water, which is not the case with sulfuric acid.

\section{Pretreatment of Samples for Radiocarbon Dating}

Of the black pigment samples available, the largest and blackest were selected for ${ }^{14} \mathrm{C}$ dating: $\mathrm{RP} /$ 2009/003/2, RP/2009/003/13, RP/2009/003/14, RP/2009/003/29, and RP/2009/003/34. The pigments were carefully scraped (with a new scalpel for each sample) to avoid any contamination from recent carbon. All of RP/2009/003/2 (8 mg) and a part of RP/2009/003/13 (13 mg) were used to test the pretreatment protocols (as described above). Four samples were therefore left for ${ }^{14} \mathrm{C}$ dating (RP/2009/003/13, RP/2009/003/14, RP/2009/003/29, and RP/2009/003/34), weighing between 7.5 and $35.7 \mathrm{mg}$. 


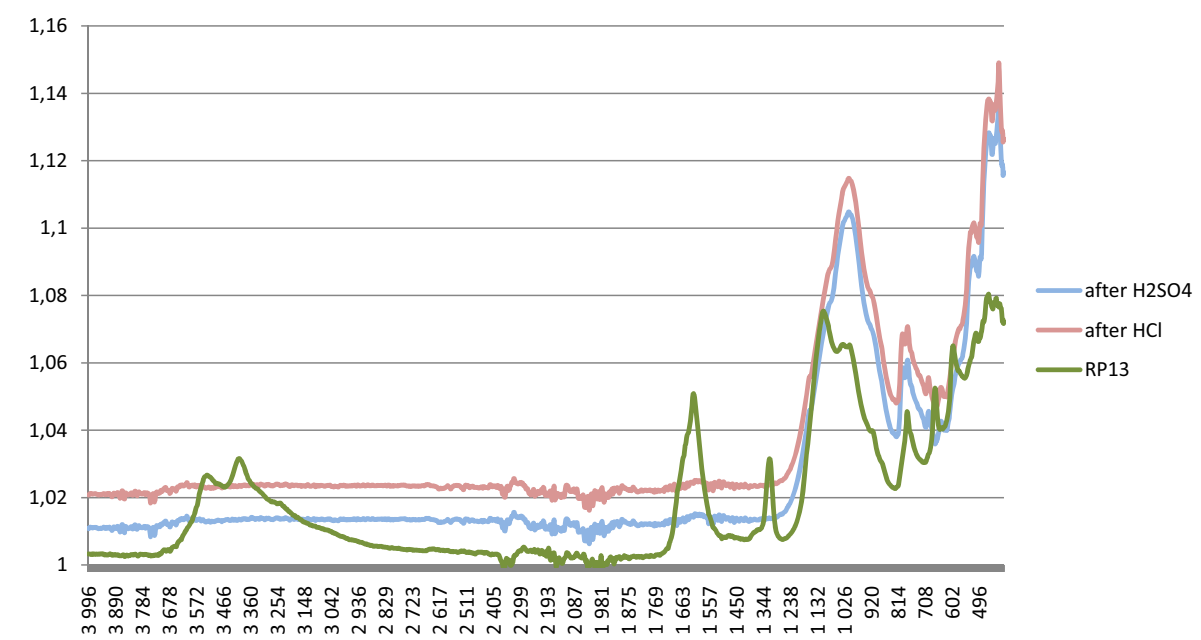

Figure 6 Spectra FTIR of sample RP/2009/003/13 before and after the acid treatment ( $x$ : wavenumber $\mathrm{cm}^{-1}$; $y$ : FTIR intensity).

Samples RP/2009/003/13, RP/2009/003/14, RP/2009/003/29, and RP/2009/003/34 were prepared using a modified acid-base-acid (ABA) protocol as follows: hydrochloric acid (1M) for $1 \mathrm{hr}$ at $80^{\circ} \mathrm{C}$ to eliminate calcium carbonates and calcium oxalates (tests with FTIR to check for elimination of these compounds were not carried out on these samples because of the very small quantity of sample remaining); $\mathrm{NaOH}(0.1 \mathrm{M})$ for $20 \mathrm{~min}$ at room temperature; and a further hydrochloric acid step (1M) for $1 \mathrm{hr}$ at $80^{\circ} \mathrm{C}$. Between each stage, the samples were washed with ultrapure Milli-Q ${ }^{\mathrm{TM}}$ water (Millipore Corp.) until neutrality. Following this preparation, the pigments were freeze-dried, after which the final products weighed 2.6-17.7 mg (see Table 1). The smallest of these, RP/2009/ $003 / 34$, was deemed too small for dating, and so was used to quantify the amount of carbon remaining in the pigments (in this case, $9.7 \% \mathrm{C}$ ) prior to dating the remaining 3 samples. These samples were combusted to $\mathrm{CO}_{2}$ and graphitized as described by Brock et al. (2010) prior to AMS dating. The graphite samples were analyzed on a small graphite wheel with standards and backgrounds of a similar size to the unknown-age archaeological samples.

\section{DISCUSSION}

Results are shown in Table 1. The determinations were calibrated with the SHCal04 curve (McCormac et al. 2004) and OxCal software v 4.1.7 (Bronk Ramsey 2009). The date range for these 3 pigments is between 2120 and $1890 \mathrm{cal} \mathrm{BP}$ (or $170 \mathrm{cal} \mathrm{BC-cal} \mathrm{AD} \mathrm{70)} \mathrm{at} 95 \%$ confidence. The measurements were carried out on 3 different fragments, which cannot be connected with any certainty to the same painting, but which belong to the same area of the same rockshelter. To try to evaluate more precisely the time of painting at the site, we modeled the ${ }^{14} \mathrm{C}$ likelihoods using a Bayesian statistical modeling method (Figure 7). The samples were assumed to belong to the same phase of prehistoric activity. The Bayesian modeling suggests that the painting activity at the site began between 2081-1952 (at 68.2\%) and 2356-1922 (95.4\%) (or from 132-3 BC at 68.2\%) and ended between 2003-1935 BP (68.2\%) and 2058-1898 BP (at 95.4\%) (or from 40 BC-72 AD at 68.2\%). These wide ranges for the start and end boundaries are indicative of the small number of determinations and the lack of constraints for the phase. These results suggest a coherent episode of painting, although given the 200-yr period this may have been made up of many separate painting events. It should not be forgotten that only 3 samples have been dated, and it is necessary to obtain more dates 
to discover more about any different phases of activity at the site and test the simple model we have built.

Table 1 Results of radiocarbon dating. The calibrated ranges were obtained using the Southern Hemisphere calibration curve (SHCal04) of McCormac et al. (2004) and OxCal v 4.1.7.

\begin{tabular}{lllllll}
\hline & \multicolumn{9}{c}{$\begin{array}{l}\text { Start } \\
\text { weight } \\
(\mathrm{mg})\end{array}$} & $\begin{array}{l}\text { End } \\
\text { weight } \\
(\mathrm{mg})\end{array}$ & $\begin{array}{l}\delta^{13} \mathrm{C} \\
(\% \text { V-PDB })\end{array}$ & Date BP & $\begin{array}{l}\text { Calibrated date } \\
(2 \sigma)\end{array}$ \\
\hline OxA-X-2370-29 & $\mathrm{RP} / 2009 / 003 / 13$ & 35.66 & 17.67 & -25.31 & $2072 \pm 28$ & $2111-1891 \mathrm{BP}$ \\
OxA-X-2370-30 & $\mathrm{RP} / 2009 / 003 / 14$ & 13.53 & 4.87 & -24.07 & $2100 \pm 40$ & $2123-1896 \mathrm{BP}$ \\
OxA-X-2370-31 & $\mathrm{RP} / 2009 / 003 / 29$ & 18.63 & 6.05 & -23.61 & $2083 \pm 32$ & $2060-1882 \mathrm{BP}$ \\
& $\mathrm{RP} / 2009 / 003 / 34$ & 7.51 & 2.63 & & & \\
\hline
\end{tabular}

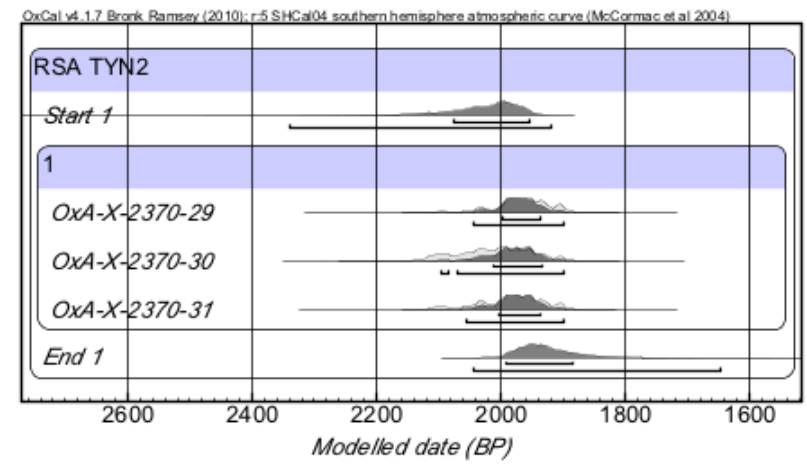

Figure 7 Dates modeled by the Bayesian model

The dates are all in close temporal agreement, which tends to suggest a reproducible preparation of the samples and low residual contamination. Rockshelters are subjected to various possible contaminants coming from bacteria, plants, animals, and humans. Moreover, the fact that the fragments lay on the ground of the shelter could also introduce recent ${ }^{14} \mathrm{C}$ contamination. The presence of random contaminants might, however, be expected to produce dates that are much more disparate, which is not the case with these results.

\section{CONCLUSION}

Direct dating of San pigments has only previously been achieved on 1 painting, in 1981 (van der Merwe et al. 1987). Our study is therefore only the second direct dating attempt. Importantly, our protocol takes into account the calcium oxalate contribution to the pigment. The experimental data shows that we have removed this material from the pigment, or at the very least left only a very minor contribution. Our results thus show that these paintings were made in the southern Drakensberg between 2120 and 1890 cal BP (170 cal BC-cal AD 70) at 95\% confidence. Few excavations have been undertaken in the area of our site, and consequently the time period in which these dates fall - the Later Stone Age - is poorly understood in the area, with few dates available. It does seem, however, that hunter-gatherers occupied the area from $~ 3000 \mathrm{yr}$ ago until historical times (Opperman 1987, 1999). The probable dates for the paintings therefore fit well within the known period of occupation. Some recent research has argued that paintings in the area were made within the $200 \mathrm{yr}$ 
in contexts of colonial contact (Blundell 2004). These dates, therefore, have the potential to dramatically alter understandings of the historical processes that led to the making of the paintings.

Besides the empirical results, the success in dating the paint is encouraging because it demonstrates the possibility of dating San pigments directly and opens the way to dating intact wall paintings. The ability to date paintings will allow additional dimensions to be added to interpretations of these paintings.

\section{ACKNOWLEDGMENTS}

The authors thank the Pigmentum Project (London, UK) and the Scientific Research Department (British Museum, UK) for the use of their instruments and their valuable advice. We are particularly grateful to Janet Ambers (British Museum), Bhavini Gorcia and Nicolas Eastaugh (Pigmentum Project), Peter Ditchfield, Mike Dee and Katerina Douka (RLAHA) for their valuable help and advice during this analysis. The Oxford ${ }^{14} \mathrm{C}$ determinations were funded by a grant from the NERC/ AHRC National Radiocarbon Facility (NRCF). We thank the staff of the Oxford Radiocarbon Accelerator Unit for their input on these samples. The financial assistance of the French Rotary Club, the Conseil Général de l'Allier, and the RLAHA towards this research is hereby acknowledged.

\section{REFERENCES}

Blundell G. 2004. Nqabayo's Nomansland: San Rock Art and the Somatic Past. Uppsala: Uppsala University Press.

Bonneau A, Pearce DG, Pollard AM. 2011. A multitechnique characterization and provenance study of the pigments used in San rock art, South Africa. Journal of Archaeological Science, in press.

Brock F, Higham T, Ditchfield P, Bronk Ramsey C. 2010. Current pretreatment methods for AMS radiocarbon dating at the Oxford Radiocarbon Accelerator Unit (ORAU). Radiocarbon 52(1):103-12.

Bronk Ramsey C. 2009. Bayesian analysis of radiocarbon dates. Radiocarbon 51(1):337-60.

Denninger E. 1971. The use of paper chromatography to determine the age of albuminous binders and its applications to rock paintings. South African Journal of Science Supplement to the Special Issue 2:80-4.

Douka K, Hedges REM, Higham TFG. 2010. Improved AMS ${ }^{14} \mathrm{C}$ dating of shell carbonates using high-precision X-ray diffraction (XRD) and a novel density separation protocol (CarDS). Radiocarbon 52(2):735-51.

Edwards HGM, Jorge Villar SE, Eremin KA. 2004. Raman spectroscopic analysis of pigments from dynastic Egyptian funerary artefacts. Journal of Raman Spectroscopy 35(8-9):786-95.

Garate D, Laval E, Menu M. 2004. Etude de la matière colorante de la grotte d'Arenaza (Galdames, Basque Country, Spain). L'Anthropologie 108(2):251-89.

Jeffery PG. 1975. Chemical Methods of Rock Analysis. Exeter: Pergamon Press.

Jerardino A, Swanepoel N. 1999. Painted slabs from Steenbokfontein Cave: the oldest known parietal art in Southern Africa. Current Anthropology 40(4):542-7.

Lewis-Williams JD, Pearce DG. 2004. San Spirituality:
Roots, Expression, and Social Consequences. Walnut Creek: AltaMira.

Livingston A, Robinson E, Armitage RA. 2009. Characterizing the binders in rock paintings by THM-GCMS: La Casa de Las Golondrinas, Guatemala, a cautionary tale for radiocarbon dating. International Journal of Mass Spectrometry 284(1-3):142-51.

Mazel AD. 2009a. Unsettled times: shaded polychrome paintings and hunter-gatherer history in the southeastern mountains of southern Africa. Southern African Humanities 21:85-115.

Mazel AD. 2009b. Images in time: advances in the dating of Maloti-Drakensberg rock art since the 1970s. In: Mitchell P, Smith B, editors. The Eland's People. New Perspectives in the Rock Art of the Maloti-Drakensberg Bushmen: Essays in Memory of Patricia Vinnicombe. Johannesburg: Wits University Press. p 81-97.

Mazel AD, Watchman AL. 1997. Accelerator radiocarbon dating of Natal Drakensberg paintings: results and implication. Antiquity 71(272):445-9.

Mazel AD, Watchman AL. 2003. Dating rock paintings in the uKhahlamba-Drakensberg and the Biggarsberg, KwaZulu-Natal, South Africa. Southern African Humanities 15:59-73.

McCormac FG, Hogg AG, Blackwell PG, Buck CE, Higham TFG, Reimer PJ. 2004. SHCal04 Southern Hemisphere calibration, 0-11.0 cal kyr BP. Radiocarbon 46(3):1087-92.

Menu M. 2009. L'analyse de l'art préhistorique. L'Anthropologie 113(3-4):547-58.

Opperman H. 1987. The Later Stone Age of the Drakensberg Range and its Foothills. Cambridge Monographs in African Archaeology 19. Oxford: BAR International Series 339. 
Opperman H. 1999. A 300 year-old living floor in Strathalan Cave A, Maclear District, Eastern Cape. Southern African Field Archaeology 8:76-80.

Pager H. 1971. Ndedema: a Documentation of the Rock Paintings of the Ndedema Gorge. Graz: Akademische Druck.

Pearce DG. 2010a. The Harris matrix technique in the construction of relative chronologies of rock paintings in South Africa. South African Archaeological Bulletin 65(191):148-53.

Pearce D. 2010b. Conservation and management of collapsing rock paintings: three sites in Maclear District, Eastern Cape Province, South Africa. South African Archaeological Bulletin 65(191):96-103.

Russ J, Hyman M, Shafer HJ, Rowe MW. 1991. ${ }^{14} \mathrm{C}$ dating of ancient rock art: a new application of plasma chemistry. Plasma Chemistry and Plasma Processing 11(4):515-27.

Russell T. 2000. The application of the Harris Matrix to San rock art at Main Caves North, KwaZulu-Natal.
South African Archaeological Bulletin 55:60-70.

Stuart B. 2007. Analytical Techniques in Materials Conservation. Chichester: Wiley.

Swart J. 2004. Rock art sequences in uKhahlamba-Drakensberg Park, South Africa. Southern African Humanities 16:13-35.

van der Merwe NJ, Sealy J, Yates R. 1987. First accelerator carbon-14 date for pigment from a rock painting. South African Journal of Science 83(1):56-7.

Vinnicombe P. 1976. People of the Eland: Rock Paintings of the Drakensberg Bushmen as a Reflection of their Life and Thought. Pietermaritzburg: University of Natal Press.

Watchman AL. 1990. A summary of occurrence of oxalate-rich crusts in Australia. Rock Art Research 7(1): 44-50.

Wendt WE. 1976. 'Art mobilier' from the Apollo 11 cave, South West Africa: Africa's oldest dated works of art. South African Archaeological Bulletin 31:5-11. 